\title{
Cyclic hexapeptide-conjugated nanoparticles enhance curcumin delivery to glioma tumor cells and tissue
}

This article was published in the following Dove Press journal:

International Journal of Nanomedicine

8 August 2017

Number of times this article has been viewed

\author{
Xuemei Zhang ${ }^{1-3}$ \\ Xuejuan $\mathrm{Li}^{1,4}$ \\ Hongchen Hua' \\ Aiping Wang' \\ Wanhui Liu'-3 \\ Youxin $\mathrm{Li}^{\mathrm{I}-3}$ \\ Fenghua $\mathrm{Fu}^{1-3}$ \\ Yanan $\mathrm{Shi}^{5}$ \\ Kaoxiang Sun'
}

'School of Pharmacy, Yantai

University, Yantai, Shandong Province,

People's Republic of China; ${ }^{2}$ State

Key Laboratory of Long-acting

and Targeting Drug Delivery

System, Yantai, Shandong Province,

People's Republic of China; ${ }^{3}$ Luye

Pharmaceutical Co., Ltd., Shandong

Province, People's Republic of China;

${ }^{4}$ National Engineering and Technology

Research Center of Chirality

Pharmaceutical, Lunan Pharmaceutical

Group Co., Ltd., Shandong Province,

People's Republic of China; ${ }^{5}$ School of

Pharmacy, Binzhou Medical University,

Shandong Province, People's Republic

of China
Correspondence: Kaoxiang Sun

School of Pharmacy, Yantai University,

No 32 Qingquan Road, Yantai

264005, Shandong Province,

People's Republic of China

Tel +865353808266

Fax +865356706066

Email sunkx@ytu.edu.cn
Abstract: Glioma has one of the highest mortality rates among primary brain tumors. The clinical treatment for glioma is very difficult due to its infiltration and specific growth locations. To achieve improved drug delivery to a brain tumor, we report the preparation and in vitro and in vivo evaluation of curcumin nanoparticles (Cur-NPs). The cyclic hexapeptide c(RGDf(N-me) VK)-C (cHP) has increased affinity for cells that overexpress integrins and was designed to target Cur-NPs to tumors. Functional polyethyleneglycol-modified poly(D,L-lactide-co-glycolide) (PEG-PLGA) conjugated to cHP was synthesized, and targeted Cur-NPs were prepared using a self-assembly nanoprecipitation process. The physicochemical properties and the in vitro cytotoxicity, accuracy, and penetration capabilities of Cur-NPs targeting cells with high levels of integrin expression were investigated. The in vivo targeting and penetration capabilities of the NPs were also evaluated against glioma in rats using in vivo imaging equipment. The results showed that the in vitro cytotoxicity of the targeted cHP-modified curcumin nanoparticles (cHP/Cur-NPs) was higher than that of either free curcumin or non-targeted Cur-NPs due to the superior ability of the cHP/Cur-NPs to target tumor cells. The targeted cHP/Cur-NPs, $\mathrm{c}(\mathrm{RGDf}(\mathrm{N}-\mathrm{me}) \mathrm{VK})$-C-modified Cur-NPs, exhibited improved binding, uptake, and penetration abilities than non-targeting NPs for glioma cells, cell spheres, and glioma tissue. In conclusion, $\mathrm{c}(\mathrm{RGDf}(\mathrm{N}-\mathrm{me}) \mathrm{VK})-\mathrm{C}$ can serve as an effective targeting ligand, and cHP/Cur-NPs can be exploited as a potential drug delivery system for targeting gliomas.

Keywords: glioma targeting, integrin targeting, c(RGDf(N-me)VK)-C peptide, curcumin nanoparticles, in vitro and in vivo evaluation

\section{Introduction}

Glioma has one of the highest mortality rates among primary brain tumors and accounts for $\sim 50 \%-60 \%$ of all brain tumors, with a median survival time of $\sim 14$ months and a 5 -year survival rate near zero. ${ }^{1}$ Glioma carries a poor prognosis and is histologically characterized by vascular proliferation and necrosis. Surgical excision is the primary clinical treatment option. However, it is very difficult to distinguish tumor tissue from normal brain tissue due to its infiltration and specific growth locations, and therefore, the tumor usually cannot be completely removed. ${ }^{2}$ Chemotherapeutic drugs rarely reach brain tumor cells due to the blood-brain barrier (BBB), and such drugs also have side effects on normal tissues and cells. All of these factors contribute to the poor efficacy of glioma treatment. ${ }^{3,4}$ As physicians and biologists have expanded the understanding of the physiological mechanisms of glioma formation and maintenance, adding molecularly targeted materials to common chemotherapies for the treatment of gliomas is a favorable approach and achieves good benefits. However, these therapeutic 
effects are limited by several factors, including molecular heterogeneity and the BBB. ${ }^{5}$ Therefore, overcoming these obstacles is an important research topic in glioma treatment. Some studies have suggested that gliomas are the most vascularized human tumors. The transition of gliomas from low to high grade is often accompanied by angiogenesis and changes in the microvascular network. The glioma microvasculature is heterogeneous, which can influence the distribution of chemotherapeutic agents to brain tumors or lead to the development of resistance to anti-angiogenic therapies. ${ }^{6}$ Concurrently, the angiogenesis process produces many invasion inhibitors, including vascular endothelial growth factor receptor (VEGFR), epidermal growth factor receptor (EGFR), hepatocyte growth factor, and integrins. Among these, integrin has been shown to be involved in promoting glioma adhesion, migration, and angiogenesis. ${ }^{7}$ Anti-angiogenic drugs have been applied in clinical studies for treatment of neoplastic and non-neoplastic diseases. Cilengitide $c(\mathrm{RGDf}(\mathrm{N}-\mathrm{me}) \mathrm{V})$ was the first anti-angiogenic small molecule discovered that targets $\alpha_{\mathrm{v}} \beta_{3}, \alpha_{\mathrm{v}} \beta_{5}$, and $\alpha_{5} \beta_{1}$ integrins. Although the Phase III clinical study evaluating cilengitide for the treatment of glioblastomas failed, integrin targeting remains a potential treatment strategy for neoplastic diseases such as glioma. ${ }^{8}$

Invasive angiogenesis also disrupts the $\mathrm{BBB}$ in patients with glioma. For this reason, many researchers have been arguing for years that the BBB was not an important obstacle in influencing the delivery and efficacy of therapies targeting glioma. ${ }^{9}$ However, all glioma patients have some percentage of their $\mathrm{BBB}$ intact, and this region of the $\mathrm{BBB}$ can prevent the distribution of chemotherapy drugs into tumor cells. Scientists have been researching multiple approaches to penetrate the $\mathrm{BBB}$, many of which have been reviewed by Oberoi et al. ${ }^{5}$ Earlier techniques to disrupt the BBB included osmotic pumps, ultrasound, and pharmacological agents; however, these approaches were limited by their toxic side effects, complexity, or poor clinical efficacy. The next issue is how to overcome the active efflux in the BBB. ${ }^{5}$ It is difficult to change the distribution of most molecularly targeted agents in tumors and tissues with changes in the expression of transporters. Recent studies have focused on nanoparticle drug carriers and peptide-based drug delivery to overcome the BBB. The method by which the drug is loaded or linked to the molecular targeting peptides or ligands affects targeting of the BBB. In most cases, these nanoparticles (NPs) or delivery systems penetrate the BBB via receptormediated endocytosis. ${ }^{10}$ Among these targeting peptides and ligands, the cyclic Arg-Gly-Asp (RGD) sequence peptide has been reported more frequently in the treatment of glioma., Moreover, some cyclic RGD sequence peptides such as iRGD (CRGDK/RGPD/EC), a tumor-homing peptide, can deliver the drug deep into the tumor parenchyma. ${ }^{11}$

Plant extracts such as curcumin, which is derived from turmeric, have been recently explored as candidates for cancer therapy due to their broad anti-angiogenic and pro-apoptotic properties. In addition, curcumin was reported to have the capacity to block the proliferation, migration, and invasion of glioma cells. ${ }^{12}$ However, the therapeutic applications of curcumin remain limited due to its low water solubility ${ }^{13}$ and poor systemic bioavailability, as patients would require $8-10 \mathrm{~g}$ of oral curcumin daily to achieve a therapeutic effect. ${ }^{14}$ One method of improving the bioavailability of curcumin is to increase its targeting capacity to tumors. NPs are believed to be suitable to deliver curcumin to tumors, and a series of curcumin nanoformulations have been studied over the past decade. ${ }^{13}$ However, the use of curcumin nanoparticles (Cur-NPs) for the treatment of glioma has not been studied due to the lack of an effective targeting ligand to deliver the drug through the BBB.

\section{Materials and methods Materials}

Cyclic peptides (purity $>95 \%$ ) and fluorescein isothiocyanate (FITC)-labeled cyclic peptides (purity $>95 \%$ ) were synthesized by ChinaPeptides Co., Ltd. (Shanghai, China). FITC-labeled immunoglobulin G1 (IgG1) was purchased from Abcam Trading (Shanghai) Co., Ltd. (Shanghai, China). 1,1'-Dioctadecyl-3,3,3', $3^{\prime}$-tetramethylindotricarbocyanine iodide (DiR iodide) and Hoechst33342 were purchased from Fanbo Biochemicals Co., Ltd. (Beijing, China). 3-(4,5-Dimethylthiazol-2-Yl)-2,5-diphenyltetrazolium bromide (MTT) was purchased from Aladdin Industrial Inc. (Shanghai, China). Maleimide-poly(ethylene glycol)poly(lactic-co-glycolide) (mal-PEG-PLGA, 20,000:5,000 Da) was purchased from PolySciTech (West Lafayette, IN, USA). mPEG5000-PLGA20000 90/10 was purchased from Jinan Daigang Biomaterial Co., Ltd. (Jinan, China). Curcumin was purchased from Shanghai Zhanyun Biological Technology Co., Ltd. (Shanghai, China). Dulbecco's Modified Eagle's Medium (DMEM), Minimum Essential Medium (MEM), and RPMI 1640 cell culture media were purchased from Gibco ${ }^{\circledR}$ Roswell Park Memorial Institute (Grand Island, NA, USA). All other materials were reagent grade and obtained from commercial suppliers.

Human umbilical vein endothelial cells (HUVECs), HeLa human breast cancer cells, and C6 malignant glioma cells 
were purchased from Institute of Basic Medical Sciences, Chinese Academy of Medical Sciences (Peking, China), and kindly supplied by Shandong Luye Pharmaceutical Co., Ltd. BALB/c-nu nude mice and Sprague-Dawley (SD) rats were supplied by Beijing Vital River Laboratory Animal Technology Co., Ltd. (Beijing, China). The Experimental Animal Research Committee at Yantai University approved this study, and all animal studies were performed in accordance with the Regulations of Experimental Animal Administration (State Food and Drug Administration, 2003).

\section{Screening of cyclic peptides}

To obtain high-affinity peptides for integrins, a computer simulation molecular docking method was used to screen and evaluate peptides. We modified the structure of a widely known cyclic RGD peptide c(RGDf(N-Me)V) by introducing lysine and cysteine to yield the presence of active sulfhydryl to allow the peptide to easily couple with the polymer carrier. The new peptide structures were screened and evaluated using computer-aided drug discovery software (SYBYL-X 2.0, Tripos Inc., St Louis, MO, USA), and the preferred peptides were then further evaluated using in vitro cell assays.

The method of molecular docking is summarized as follows: the crystal structure data of the extracellular segment of integrin $\alpha_{\mathrm{v}} \beta_{3}$ in complex with c(RGDf(N-Me)V) ligand $(1 \mathrm{~L} 5 \mathrm{G})^{15}$ was downloaded from the Protein Data Bank (PDB); the $\mathrm{H}_{2} \mathrm{O}$ and ligand were removed from the complex crystal structure, and the residual structure was subsequently used for molecular docking after hydrogenation.

Here, the docking functions of SYBYL-X2.0 were utilized. Some previously reported RGD peptides were docked with the above residual structure, and the score was obtained depending on Hammerhead scoring function combined with electrostatic forces, van der Waals forces, hydrophobic interactions, and hydrogen bonding. The parameters used in the docking process were adjusted according to the score sequence and the reported binding affinity with integrin $\alpha_{\mathrm{v}} \beta_{3}{ }^{16}$

New cyclic hexapeptides based on c(RGDf(N-Me)V) were designed considering previously reported structureactivity relationships, ${ }^{17}$ the required structure covalent coupled with the polymer carrier, and the synthesizability of the structure. These cyclic hexapeptides were docked with the residual integrin structure and they scored based on the above parameters. A cyclic hexapeptide c(RGDf(N-me) $\mathrm{VK})-\mathrm{C}$ was obtained for further study based on the docking score sequence.
Cell affinity evaluation of cyclic peptides

\section{Cell culture}

HUVECs and C6 cells were selected to explore the affinity of the cyclic hexapeptides with integrin $\alpha_{\mathrm{v}} \beta_{3}$ under a high expression of integrin $\alpha_{\mathrm{v}} \beta_{3}{ }^{18}$ We cultured HUVECs in DMEM and C6 cells in MEM (both media were supplemented with $10 \%$ fetal bovine serum) at $37^{\circ} \mathrm{C}$ with $5 \% \mathrm{CO}_{2}$. The medium was replaced every 1-2 d, and the growth state of the cells was observed daily through an inverted microscope.

\section{Affinity evaluation of cyclic peptides}

Flow cytometry was applied in the affinity studies. Two milliliters of cell suspension $\left(1 \times 10^{5}\right.$ cells/well) was inoculated in a 6-well plate and cultured for $24 \mathrm{~h}$. The HUVECs and C6 cells were divided into two groups. The cells in group one were treated with $2 \mathrm{~mL}$ of $10 \mu \mathrm{g} / \mathrm{mL}$ FITClabeled cyclic hexapeptide-containing medium for $15 \mathrm{~min}$ at $37^{\circ} \mathrm{C}$. The cells in group two were pretreated with $2 \mathrm{~mL}$ of antibody-containing medium for $30 \mathrm{~min}$ at $37^{\circ} \mathrm{C}$. The medium contained $2 \mu \mathrm{L}$ of anti-integrin $\alpha_{\mathrm{v}} \beta_{3}$ antibodies (Abcam; 27.1 [VNR-1]). Using this procedure, the cells in group two were treated with cyclic hexapeptide-containing medium consistent with the first group. The cells were treated with blank medium as a control. All cells were collected at the prescribed times after treating with the different media, washed twice with PBS, and re-suspended in $600 \mu \mathrm{L}$ of PBS. Fluorescence data were collected using a FACS Jazz cell sorting system (BD Biosciences, San Jose, CA, USA), and the cell fluorescence and affinity were analyzed.

\section{Covalent coupling of cyclic hexapeptide to mal-PEG-PLGA}

The cyclic hexapeptide c(RGDf(N-me)VK)-C and mal-PEGPLGA were covalently coupled using a previously reported method with modifications. ${ }^{19}$ In brief, mal-PEG-PLGA was dissolved in acetone, dried with nitrogen, and hydrated overnight in HEPES ( $\mathrm{pH}=6.5$ ). mal-PEG-PLGA was then mixed with cyclic hexapeptide at a 1:1 molar ratio in HEPES $(\mathrm{pH}=6.5)$. This mixture was gently stirred at $20^{\circ} \mathrm{C}$ for at least $48 \mathrm{~h}$ under nitrogen gas. The resulting reaction samples were purified from the unreacted cyclic hexapeptide by ultrafiltration (molecular weight cutoff $=10 \mathrm{kDa}$ ). The products were collected and lyophilized to obtain cyclic hexapeptide-PEGPLGA (cHP-PP).

The amount of cyclic hexapeptide conjugated to malPEG-PLGA was determined indirectly by measuring uncoupled cyclic hexapeptide in the ultrafiltrate after the ultrafiltration step. A reverse-phase high-performance liquid 
chromatography (RP-HPLC) (Agilent 1100 system, Agilent, Santa Clara, CA, USA) system with a UV detector at $220 \mathrm{~nm}$ was used to analyze uncoupled cyclic hexapeptide in the reaction system. The chromatographic column was a Phenomenex $\mathrm{C}_{18}(4.6 \times 150 \mathrm{~mm}, 5 \mu \mathrm{m})$, and the mobile phase consisted of $0.1 \%$ trifluoroacetate (TFA) in acetonitrile and $0.1 \%$ TFA in water $(10: 90, \mathrm{v} / \mathrm{v})$. The injection volume was $20 \mu \mathrm{L}$.

\section{Characterization of synthetic functional polymers}

The cHP-PP was dissolved in $0.5 \mathrm{~mL}$ of $\mathrm{CDCl}_{3}$, after which, nuclear magnetic resonance spectroscopy (Advance Bruker 400 M, Bruker Company, Fällanden, Switzerland) was used to identify the reaction product.

\section{Preparation of NPs and cHP-modified nanoparticles (cHP-NPs)}

NPs and cHP-NPs were prepared via one-step nanoprecipitation with different ratios of cHP-PP, methoxy-poly(ethylene glycol)-poly(lactic-co-glycolic acid) (mPEG-PLGA), curcumin, DiR, or coumarin (Cou). Here, curcumin acts as the drug entrapped in the NPs and as a fluorescent probe in the in vitro cell evaluation. DiR and coumarin were used as fluorescent indicators in the in vivo targeting evaluation of the NPs due to the weak fluorescence of curcumin in such conditions. The average molecular weights of PEG and PLGA in mPEG-PLGA were 5 and $20 \mathrm{kDa}$, respectively. According to the proposed formulation table (Table 1), mPEG-PLGA, cHP-PP, curcumin, DiR, or coumarin was added to $2 \mathrm{~mL}$ of acetone solution to prepare the oil phase. Under stirring, the oil phase was dropped into $20 \mathrm{~mL}$ of purified water. The suspension system was then stirred uncovered for at least $4 \mathrm{~h}$ at $20^{\circ} \mathrm{C}$ to evaporate the acetone. To determine the incorporation efficiency of curcumin in NPs or cHP-NPs, the NP suspensions were centrifuged (10 $\mathrm{min}, 10 \mathrm{krpm})$, and the supernatant was analyzed using an RP-HPLC (Agilent 1100 system, Agilent, Santa Clara, CA, USA) system with a UV detector at $425 \mathrm{~nm}$. The chromatographic column was a Phenomenex $\mathrm{C}_{18}$ column $(4.6 \times 150 \mathrm{~mm}, 5 \mu \mathrm{m})$, and the mobile phase consisted of acetonitrile with $0.5 \%$ acetic acid in water $(60: 40, v / v)$. The injection volume was $20 \mu \mathrm{L}$, and the flow speed was $1.0 \mathrm{~mL} / \mathrm{min}^{1}$. The final NPs were purified, collected by ultrafiltration (15 min, 3,000 rpm, MW $30 \mathrm{kDa}$ ), and lyophilized. The particle size and polydispersity of the resulting NPs were detected with a dynamic light scattering (DLS) particle size analyzer (Nicomp 380 ZLS; PSS, Port Richey, FL, USA). The surface morphology of the NPs was examined using a transmission electron microscope (TEM) (JEM 1400, JOEL, Tokyo, Japan).

\section{In vitro cytotoxicity assay}

The cytotoxicity of the prepared free curcumin and its NPs was determined using the MTT assay. C6 cells and HeLa cells were seeded in 96-well plates at $1 \times 10^{4}$ cells per well in $100 \mu \mathrm{L}$ of corresponding media. The cells were incubated at $37^{\circ} \mathrm{C}$ in $5 \% \mathrm{CO}_{2}$ for $24 \mathrm{~h}$ followed by treatment with increasing concentrations $(1.25-40 \mu \mathrm{M})$ of either free curcumin or the Cur-NPs (Cur-NP, cHP-modified curcumin nanoparticles [cHP/Cur-NPs]) for 24, 48, and $72 \mathrm{~h}$; the cells were then incubated in $5 \% \mathrm{CO}_{2}$ at $37^{\circ} \mathrm{C}$. Subsequently, $20 \mu \mathrm{L}$ of MTT solution $(5 \mathrm{mg} / \mathrm{mL})$ was added per well and incubated with the cells for $4 \mathrm{~h}$. Next, the culture medium was discarded, and $200 \mu \mathrm{L}$ of DMSO was used to dissolve the formazan crystals. After the plate was gently shaken for $10 \mathrm{~min}$, the absorbance at $570 \mathrm{~nm}$ of each well was measured using a microplate reader (SpectraMax M5, Molecular Devices Corporation, Sunnyvale, CA, USA). The data are shown as the percentage of viable cells per sample compared with the survival of the control group (untreated cells were used as the control group, and the cell viability of this group was set to $100 \%$ ).

Table I Composition of NPs and cHP-NPs

\begin{tabular}{|c|c|c|c|c|c|c|c|}
\hline & $\begin{array}{l}\text { mPEG-PLGA } \\
(\mathrm{mg})\end{array}$ & $\begin{array}{l}\text { cHP-PP } \\
(\mathrm{mg})\end{array}$ & $\begin{array}{l}\text { Curcumin } \\
\text { (mg) }\end{array}$ & $\begin{array}{l}\text { DiR } \\
(\mathrm{mg})\end{array}$ & $\begin{array}{l}\text { Coumarin } \\
(\mathrm{mg})\end{array}$ & $\begin{array}{l}\text { Acetone } \\
(\mathrm{mL})\end{array}$ & $\begin{array}{l}\text { Purified water } \\
\text { (mL) }\end{array}$ \\
\hline NPs & 20.0 & I & I & I & I & 2.0 & 20.0 \\
\hline cHP-NPs & 15.0 & 5.0 & l & l & I & 2.0 & 20.0 \\
\hline Cur-NPs & 20.0 & I & 1.0 & & I & 2.0 & 20.0 \\
\hline cHP/Cur-NPs & 15.0 & 5.0 & 1.0 & & I & 2.0 & 20.0 \\
\hline Cou-NPs & 20.0 & I & I & & 0.1 & 2.0 & 20.0 \\
\hline cHP/Cou-NPs & 15.0 & 5.0 & I & & 0.1 & 2.0 & 20.0 \\
\hline DiR-NPs & 20.0 & & 1 & 0.15 & I & 2.0 & 20.0 \\
\hline cHP/DiR-NPs & 15.0 & 5.0 & l & 0.15 & I & 2.0 & 20.0 \\
\hline
\end{tabular}

Note: "/"means not used in this formulation.

Abbreviations: cHP, cyclic hexapeptide, c(RGDf(N-me)VK)-C; cHP/Cou-NPs, cHP-modified coumarin nanoparticles; cHP/Cur-NPs, cHP-modified curcumin nanoparticles; cHP/DiR-NPs, cHP-modified DiR nanoparticles; cHP-NPs, cHP-modified nanoparticles; cHP-PP, cHP-modified methoxy-poly(ethylene glycol)-poly(lactic-co-glycolic acid); Cou-NPs, coumarin nanoparticles; Cur-NPs, curcumin nanoparticles; DiR, I, I'-Dioctadecyl-3,3,3',3'-tetramethylindotricarbocyanine; DiR-NPs, DiR nanoparticles; mPEGPLGA, methoxy-poly(ethylene glycol)-poly(lactic-co-glycolic acid); NPs, nanoparticles. 


\section{Targeting and penetration capabilities of the NPs}

In vitro cellular targeting of $\mathrm{C} 6$ cells by NPs

The $\mathrm{C} 6$ cells were seeded in 6 -well plates $\left(1 \times 10^{5}\right.$ cells in $2 \mathrm{~mL}$ per well) and incubated for $24 \mathrm{~h}$ at $37^{\circ} \mathrm{C}$. The cultured medium was replaced with $2 \mathrm{~mL}$ of medium containing different NPs (Cur-NP, cHP/Cur-NP; the curcumin concentration in the NPs was $2-10 \mu \mathrm{M}$ ). The cells were harvested by trypsin and centrifuged after 30, 60, and 90 min of incubation at $37^{\circ} \mathrm{C}$. The percentage of fluorescent cells in each NP group was subsequently measured by flow cytometry (FACS, BD FACSJazz, BD Biosciences, San Jose, CA, USA), and the cellular uptake efficiency was calculated. Cells not treated with NPs served as the control group.

To investigate the targeting mechanism of curcumin NPs, C6 cells were preincubated for $1 \mathrm{~h}$ with c(RGDf(N-me) VK)-C (40 $\mu \mathrm{M})$, the competitive inhibitor of RGD with integrin $\alpha_{\mathrm{v}} \beta_{3}$. The $\mathrm{C} 6$ cells were subsequently co-incubated with Cur-NPs or cHP/Cur-NPs at a curcumin concentration of $10 \mu \mathrm{M}$ for $90 \mathrm{~min}$ at $37^{\circ} \mathrm{C}$. The control group did not receive inhibitor treatment. The cellular uptake efficiency was determined by flow cytometry, and the data were compared between the test group and the control group.

\section{In vitro cellular penetration of NPs to C6 spheroids}

In vitro C6 spheroids were established using a previously reported method ${ }^{20}$ with a lipid overlay system. C6 cells $\left(2 \times 10^{3}\right.$ cells/well) were seeded in $200 \mu \mathrm{L}$ of culture medium in a 96-well plate loaded with $2 \%(\mathrm{~m} / \mathrm{V})$ agarose in basal DMEM. After the cells were cultured for $5 \mathrm{~d}$ at $37^{\circ} \mathrm{C}$ in an atmosphere containing $5 \% \mathrm{CO}_{2}$, they slowly aggregated to form a solid sphere. The tumor cell spheroids were then incubated with $200 \mu \mathrm{L}$ of medium containing NPs, coumarin nanoparticles (Cou-NPs), or cHP-modified coumarin nanoparticles (cHP/ Cou-NPs) (the concentration of coumarin was $2 \mu \mathrm{M}$ ) for 1 , 2 , or $4 \mathrm{~h}$. After the plates were washed three times with PBS, the spheroids were observed via confocal laser scanning microscopy (CLSM, Olympus FV1000, Olympus Corporation, Tokyo, Japan) to investigate NP penetration.

\section{In vivo evaluation}

\section{In vivo targeting evaluation of NPs in a rat glioma} model

Adult male SD rats (180-220 g) were randomly divided into a sham operation group, a model group, and a blank group and provided free access to chow and water. The number of rats in the three groups was 6, 4, and 4, respectively. Before surgery, all of the rats were anesthetized with $10 \%$ chloral hydrate
( $4 \mathrm{~mL} / \mathrm{kg}$ intraperitoneally). A small incision was made through the right hemisphere. A stereotactic apparatus (Neurostar, Tübingen, Germany) was used for head fixation and location. A high-speed drill was used to create a hole $\sim 1.0 \mathrm{~mm}$ in diameter at $1.0 \mathrm{~mm}$ anterior of the bregma coronal suture and $3.0 \mathrm{~mm}$ right lateral of the sagittal suture. A total of $10 \mu \mathrm{L}$ $\left(1 \times 10^{6}\right.$ cells $)$ of $\mathrm{C} 6$ cells was transplanted into the caudate nucleus of the rats using a Hamilton syringe through the drilled holes. Ten minutes after injection, the needle was removed, and bone wax was used to fill the burr hole. The skin was sutured together, and the rats recovered. The sham operation group was injected with the same volume of PBS as described above, and the blank group was used as the control group.

One rat in each group was sacrificed with excessive $10 \%$ chloral hydrate (i.p.) on days 14 and 21 after tumor cell implantation. Brain tissues were collected for morphological observation to determine tumor establishment. After the final observation, $0.2 \mathrm{~mL}$ of DiR nanoparticles (DiR-NPs) or cHP-modified DiR nanoparticles (cHP/DiR-NPs) was injected into each group of rats ( $300 \mu \mathrm{g} / \mathrm{kg}$ intravenous [i.v.]). One rat in each group was euthanized $8 \mathrm{~h}$ after NP injection. The rat hearts were perfused with saline and then with $4 \%$ paraformaldehyde (PFA). The brains tissue and tumors were collected and fixed for $24 \mathrm{~h}$ in 3\% PFA and then cryopreserved in 3\% PFA/sucrose for $48 \mathrm{~h}$. Afterward, the tumor tissues were sliced into $10-\mu \mathrm{m}$ sections, which were fixed for 10 min with cold acetone and then washed with PBS. Then, $10 \mu \mathrm{g} / \mathrm{mL}$ Hochest33342 was added, and the sections were cultured at room temperature for $10 \mathrm{~min}$. A fluorescencequenching agent was added to seal the sections. The tumor cells and NPs that penetrated the tumor tissue were observed using CLSM.

At $1,4,8,12$, and $24 \mathrm{~h}$ after injection, the rats were anesthetized with 5\% chloral hydrate. In vivo imaging (Care stream In Vivo FX, Bruker, Madison, WI, USA) was utilized to capture images of the fluorescence distribution and assess the in vivo targeting ability of the NPs. At $8 \mathrm{~h}$ post-injection, the rats were euthanized and the brain and other organs were harvested. The fluorescent images of the brains and other organs were recorded and analyzed with Kodak MI In Vivo Fx Pro software.

\section{Results and discussion \\ Screening and affinity of the tested cyclic peptides}

The results of the simulated SYBYL-X 2.0 score, which was a comprehensive result that integrated the electrostatic interactions, van der Waals forces, hydrophobic interactions, and hydrogen bonding of the cyclic RGD peptide to integrin 
Table 2 Scores of the cyclic peptide according to computeraided drug discovery software

\begin{tabular}{ll}
\hline Cyclic peptide & Score \\
\hline c(RGDf(N-me)V) & 7.98 \\
c(RGDf(N-me)VK)-C & 11.31 \\
c(RGDfV) & 6.46 \\
c(RGDfK)-C & 7.97 \\
c(RGDfV)-GDK & 6.54 \\
c(RGDfKV) & 7.72 \\
c(RGDfKV)-C & 8.35 \\
c(RGDfKV)-GD & 6.69 \\
c(RGDKf) & 6.36 \\
c(RGDKfV)-C & 6.78 \\
\hline
\end{tabular}

$\alpha_{v} \beta_{3}$, are shown in Table 2 . It is generally accepted that scores below 4 indicate poor affinity, and scores $>7$ represent strong affinity. Among all of the peptides tested, the top three scores were observed for c(RGDf(N-me)VK)-C, c(RGDfKV)-C, and $\mathrm{c}(\mathrm{RGDf}(\mathrm{N}-\mathrm{me}) \mathrm{V})$; therefore, these three peptides were utilized in the affinity study of cells overexpressing integrin.

To evaluate the affinity of the screened cyclic peptides with integrins, a cellular uptake capability test on integrinoverexpressing cells was applied. It was previously demonstrated that HUVECs ${ }^{20}$ and $\mathrm{C} 6$ cells $^{21}$ express integrin $\alpha_{\mathrm{v}} \beta_{3}$ on their cell surface, an observation that was confirmed in our cell sorting experiment using $\alpha_{\mathrm{v}} \beta_{3}$ antibodies. Therefore, HUVECs and C6 cells were selected to explore the specificity of cyclic RGD peptides in subsequent in vitro studies.

Figure 1 shows the cellular uptake efficiency results after a 15-min treatment with FITC-labeled cyclic peptide or integrin antibody plus FITC-labeled cyclic peptide in
HUVECs and C6 cells. Prior to this experiment, we preliminarily studied the relationship between the cell uptake efficiency and treatment time of the FITC-labeled cyclic peptide medium and the concentration of FITC-labeled cyclic peptide. The specific experimental parameters were then determined as described in the methods of affinity evaluation of cyclic peptides.

According to the results, for the cyclic peptide group, the average cellular uptake efficiency of FITC-labeled c(RGDf(N-me)VK)-C (90.7\%) was significantly higher than those of FITC-labeled c(RGDfKV)-C (79.6\%) and c(RGDf(N-me)V) (53.0\%) (a, $P<0.05, \mathrm{n}=3)$ in HUVECs, and similar results for the cyclic peptide group were observed in $\mathrm{C} 6$ cells. For the second group, the average cellular uptake efficiency of FITC-labeled cyclic peptide decreased to $<25 \%$ after the HUVECs and C6 cells were treated with integrin antibody for $30 \mathrm{~min}$. Based on the uptake efficiency difference between groups 1 and 2 in HUVECs and C6 cells, we considered that the uptake efficiency of cyclic peptide was associated with the affinity between the overexpressed integrin in the cells and the cyclic peptides. FITC-labeled c(RGDf(N-me) VK)-C had a stronger ability to bind with the integrin and a stronger cellular uptake ability than the other two peptides. Therefore, $\mathrm{c}(\mathrm{RGDf}(\mathrm{N}-\mathrm{me}) \mathrm{VK})-\mathrm{C}$ was utilized as the preferred cyclic peptide in the following experiments.

\section{Characterization of the synthetic functional polymers}

Michael addition reaction occurs between c(RGDf(N-me) VK)-C with mal-PEG-PLGA in PBS (pH 6.5) yielding the

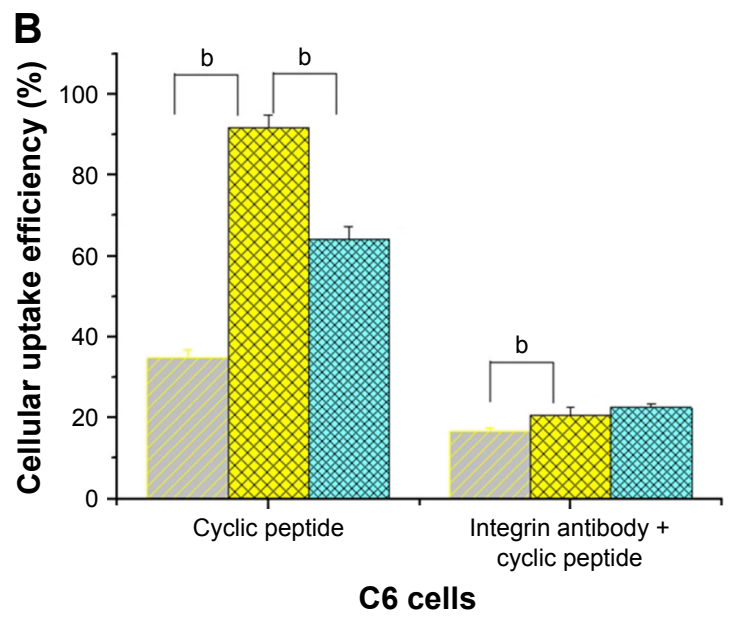

HUVEC cells

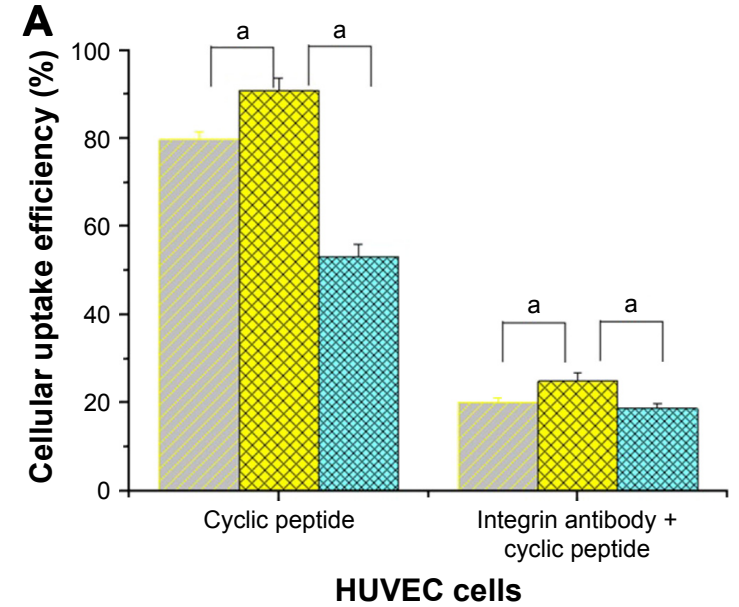

$\mathrm{c}(\mathrm{RGDfKV})-\mathrm{C} \quad \mathrm{x}$ c(RGDf(N-me)V)

Figure I Cells were incubated with $10 \mu \mathrm{g} / \mathrm{mL}$ FITC-labeled cyclic peptide or $2 \mu \mathrm{L}$ of anti-integrin $\alpha_{\mathrm{v}} \beta_{3}$ antibodies plus I0 $\mu \mathrm{g} / \mathrm{mL}$ FITC-labeled cyclic peptide for I5 min. Notes: (A) Cellular uptake efficiency of HUVECs detected by flow cytometry; ${ }^{a} P<0.05$. (B) Cellular uptake efficiency of $C 6$ cells detected by flow cytometry; ${ }^{\text {b }}<<0.05$. Abbreviations: FITC, fluorescein isothiocyanate; HUVECs, human umbilical vein endothelial cells; RGD, Arg-Gly-Asp. 
A

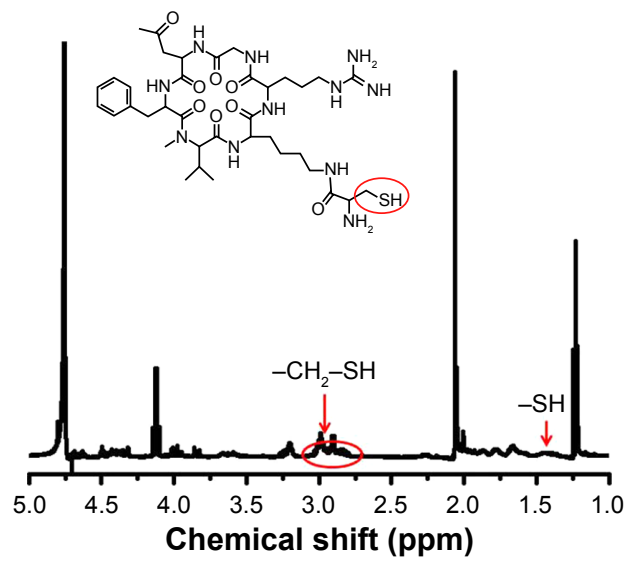

B

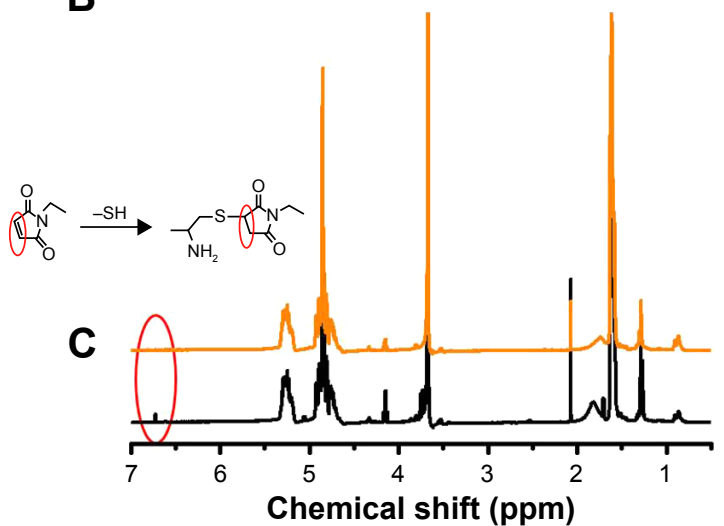

Figure 2 'H-NMR spectra of (A) c(RGDf(N-me)VK)-C, (B) mal-PEG-PLGA, and (C) cHP-PP in $\mathrm{CDCl}_{3}$.

Abbreviations: cHP, cyclic hexapeptide, c(RGDf(N-me)VK)-C; cHP-PP, cHP-modified methoxy-poly(ethylene glycol)-poly(lactic-co-glycolic acid); mal-PEG-PLGA, maleimidepoly(ethylene glycol)-poly(lactic-co-glycolide).

product cHP-PP. Figure 2 shows the ${ }^{1} \mathrm{H}-\mathrm{NMR}$ spectrum of cHP-PP. In Figure 2B, the peak $(2 \mathrm{H})$ at $\delta 6.71$ was the characteristic peak of MAL. However, the peak disappeared after binding with cyclic hexapeptide, as shown in Figure $2 \mathrm{C}$, indicating that a new substance had been generated. In Figure 2A, the peaks at $\delta 1.42,2.78$, and 2.95 are the characteristic peaks of $\mathrm{c}(\mathrm{RGDf}(\mathrm{N}-\mathrm{me}) \mathrm{VK})-\mathrm{C}$, but these are covered by the peak of mal-PEG-PLGA and therefore cannot be an indicator of cHP-PP. Content analysis via HPLC showed that the link efficiency of mal-PEG-PLGA with cyclic hexapeptide was $\sim 90 \%$.

\section{Physicochemical characteristics of NPs and cHP-NPs}

The cHP-PP synthesis and cHP-NP preparation processes are illustrated in Figure 3. We studied the physicochemical properties of different NPs with respect to particle size, polydispersity index, and encapsulation efficiency. The properties of the NPs and cHP-NPs are shown in Table 3 and Figure 4. The NPs are solid spheres, and compared with the diameter of the NPs, the mean diameter of the cHP-NPs increased as a result of coupling with cyclic hexapeptides. However, their average diameter remained $<100 \mathrm{~nm}$, which is an important factor to avoid uptake by the reticuloendothelial system. ${ }^{22}$ Similar results were noted for the NPs and cHP-NPs loaded with curcumin compared to the NPs and cHP-NPs without curcumin. In addition, this increase correlated with high drug loading. However, the particle size of the NPs and cHP-NPs was not affected by the loading of coumarin- 6 for its low drug content. The polydispersity of all the NPs presented a narrow particle size distribution. Regarding the encapsulation efficiency of either
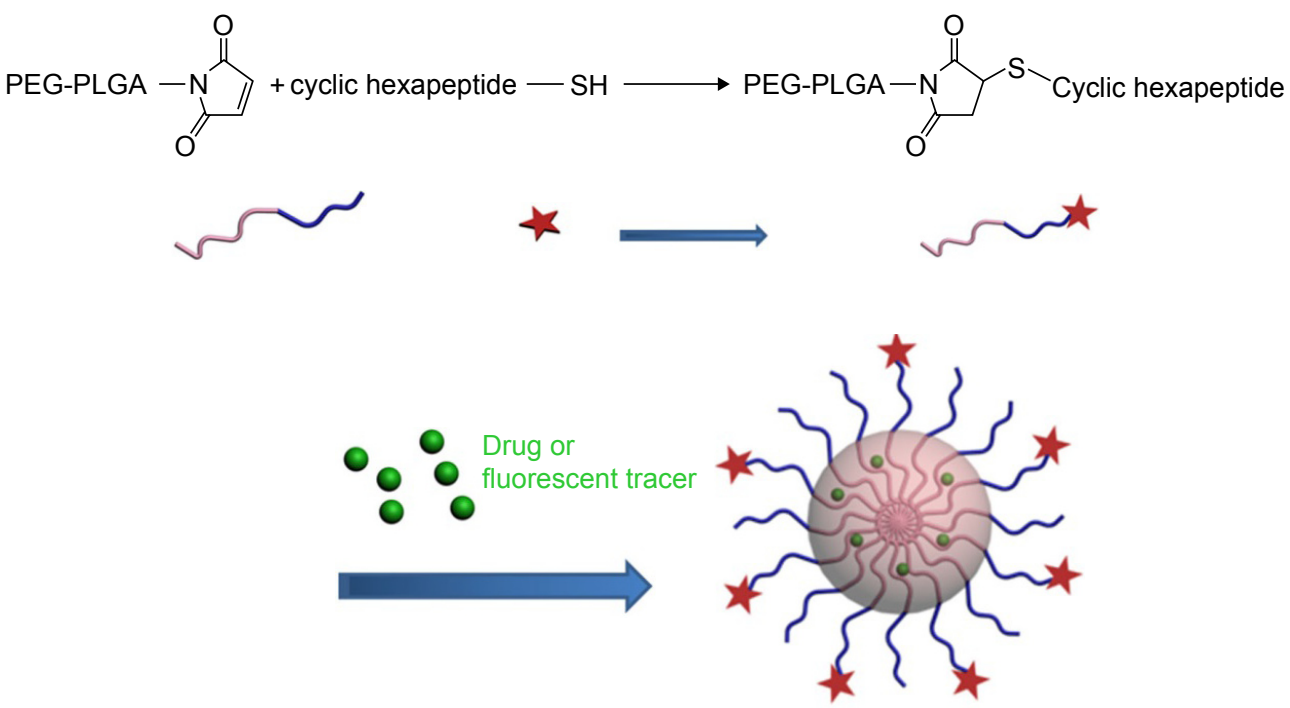

Figure 3 Schematic representation of the synthesis of cHP-PP and the preparation of cHP-NPs.

Abbreviations: cHP, cyclic hexapeptide, c(RGDf(N-me)VK)-C; cHP-NPs, cHP-modified nanoparticles; cHP-PP, cHP modified-PEG-PLGA; PEG-PLGA, poly(ethylene glycol) modified poly(lactide-co-glycolide); $\mathrm{SH}$, Mercapto. 
Table 3 Particle size and polydispersity index of NPs $(n=3)$

\begin{tabular}{llll}
\hline & $\begin{array}{l}\text { Particle size } \\
\text { (nm) }\end{array}$ & $\begin{array}{l}\text { Polydispersity } \\
\text { index }\end{array}$ & $\begin{array}{l}\text { Encapsulation } \\
\text { efficiency (\%) }\end{array}$ \\
\hline NPs & $70.5 \pm 0.8$ & $0.11 \pm 0.03$ & $/$ \\
cHP-NPs & $80.1 \pm 2.4$ & $0.17 \pm 0.05$ & $/$ \\
Cur-NPs & $78.6 \pm 1.5$ & $0.18 \pm 0.06$ & $86.08 \pm 2.58$ \\
cHP/Cur-NPs & $97.3 \pm 1.7$ & $0.16 \pm 0.04$ & $80.52 \pm 2.39$ \\
Cou-NPs & $71.5 \pm 2.9$ & $0.19 \pm 0.05$ & $92.21 \pm 3.56$ \\
cHP/Cou-NPs & $82.9 \pm 3.6$ & $0.25 \pm 0.08$ & $86.33 \pm 1.98$ \\
DiR-NPs & $70.8 \pm 2.0$ & $0.18 \pm 0.05$ & $91.58 \pm 4.58$ \\
cHP/DiR-NPs & $78.2 \pm 3.6$ & $0.22 \pm 0.07$ & $83.24 \pm 2.43$ \\
\hline
\end{tabular}

Note: "I"indicates not applicable.

Abbreviations: cHP, cyclic hexapeptide, c(RGDf(N-me)VK)-C; cHP/Cou-NPs, cHP-modified coumarin nanoparticles; cHP/Cur-NPs, cHP-modified curcumin nanoparticles; cHP/DiR-NPs, cHP-modified DiR nanoparticles; cHP-NPs, cHPmodified nanoparticles; Cou-NPs, coumarin nanoparticles; Cur-NPs, curcumin nanoparticles; DiR, I, I'-Dioctadecyl-3,3,3',3'-tetramethylindotricarbocyanine; DiRNPs, DiR nanoparticles; NPs, nanoparticles.

drug or fluorescent agent, all the NPs showed high loads of $>80 \%$. After covalently binding the cyclic hexapeptide to PEG-PLGA-MAL, the encapsulation efficiency of the cHPNPs was reduced, possibly due to the increasing internal osteoporosis observed as a result of macromolecular steric hindrance in the formation of the NPs.

\section{Cytotoxicity of free curcumin, Cur-NPs, and cHP/Cur-NPs}

C6 and HeLa cells were incubated with different concentrations of free curcumin and its NPs for 24, 48, and $72 \mathrm{~h}$. The cell viabilities of the different cell types are shown in Figure 5.

For C6 cells, high integrin $\alpha_{\mathrm{v}} \beta_{3}$-expressing cells, ${ }^{21}$ there was no significant difference between free curcumin and its NPs at low concentrations (eg, 1.25 and $2.5 \mu \mathrm{M}$ ) after a 24-h incubation before the MTT assay. However,

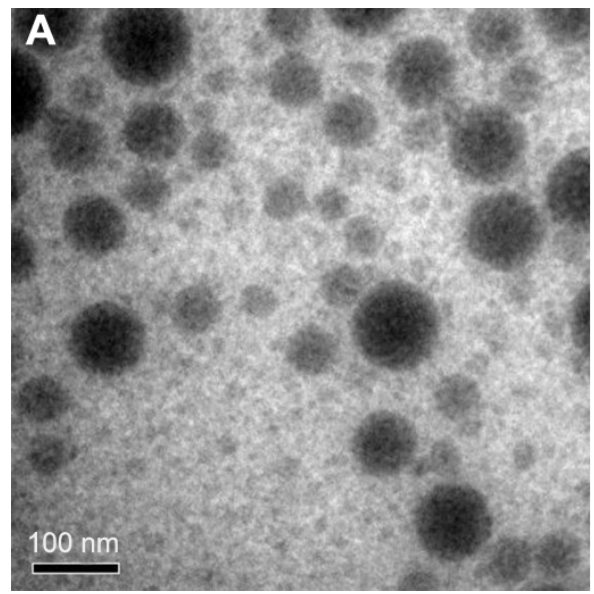

the C6 cell viability decreased with increasing curcumin concentrations and extended incubation times. When the concentrations exceeded $5 \mu \mathrm{M}$, the toxicity of Cur-NPs and cHP/Cur-NPs increased faster and was significantly higher than that of free curcumin $(P<0.05)$. At the same curcumin concentration, such as $30 \mu \mathrm{M}$ curcumin, the toxicity of the cHP/Cur-NPs $(32.4 \% \pm 2.3 \%)$ was significantly greater than that of the unmodified Cur-NPs $(51.2 \% \pm 3.1 \%)(P<0.01)$. Figure 5 shows that the cytotoxicity of curcumin and its NPs were positively correlated with the curcumin concentration and incubation time, and similar results were obtained for different incubation times.

To verify whether the increasing cytotoxicity of the curcumin NPs was caused by the toxicity of cyclic hexapeptide and nanomaterials, blank NPs and blank cHP-NPs without curcumin were prepared, and additional cytotoxicity experiments in C6 cells and HeLa cells were performed. Both types of blank NPs showed good cell compatibility and low toxicity (data not shown here). For the blank NPs, at the highest concentration of $1,600 \mu \mathrm{g} / \mathrm{mL}$ (equivalent to that in $80 \mu \mathrm{M}$ of Cur-NPs), the cell viability was still $>85 \%$ after a 72-h incubation. The cytotoxicity of blank NPs modified by cyclic hexapeptide slightly increased, which is likely due to cell growth inhibition by cyclic hexapeptide. This finding indicated that the material itself had low cytotoxicity, and, therefore, the observed cytotoxicity was caused by curcumin and its NPs.

For HeLa cells, integrin $\alpha_{v} \beta_{3}$-negative cells, ${ }^{23}$ no significant differences were identified between the free curcumin and its NPs at low curcumin concentrations for $24 \mathrm{~h}$ of incubation. The cytotoxicity increased with increasing concentrations. When the concentration in HeLa cells reached $20 \mu \mathrm{M}$ after $24 \mathrm{~h}$ of incubation, the average cell

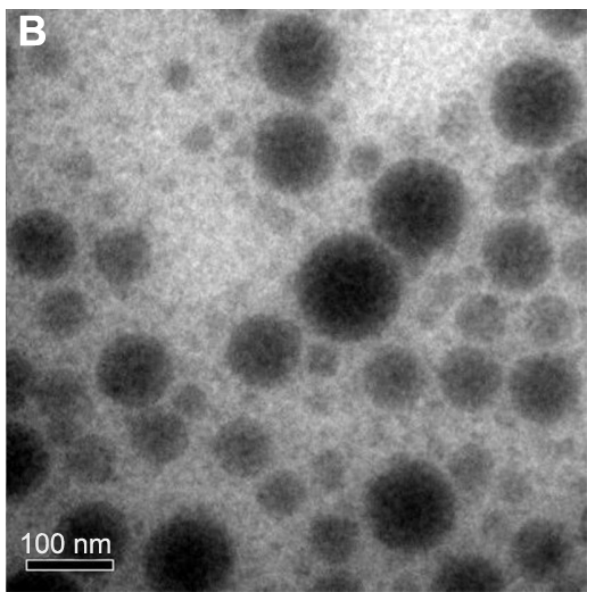

Figure 4 TEM images of Cur-NP (A) and cHP/Cur-NP (B).

Abbreviations: cHP, cyclic hexapeptide, c(RGDf(N-me)VK)-C; cHP/Cur-NP, cHP-modified curcumin nanoparticles; Cur-NP, curcumin nanoparticles; TEM, transmission electron microscope. 

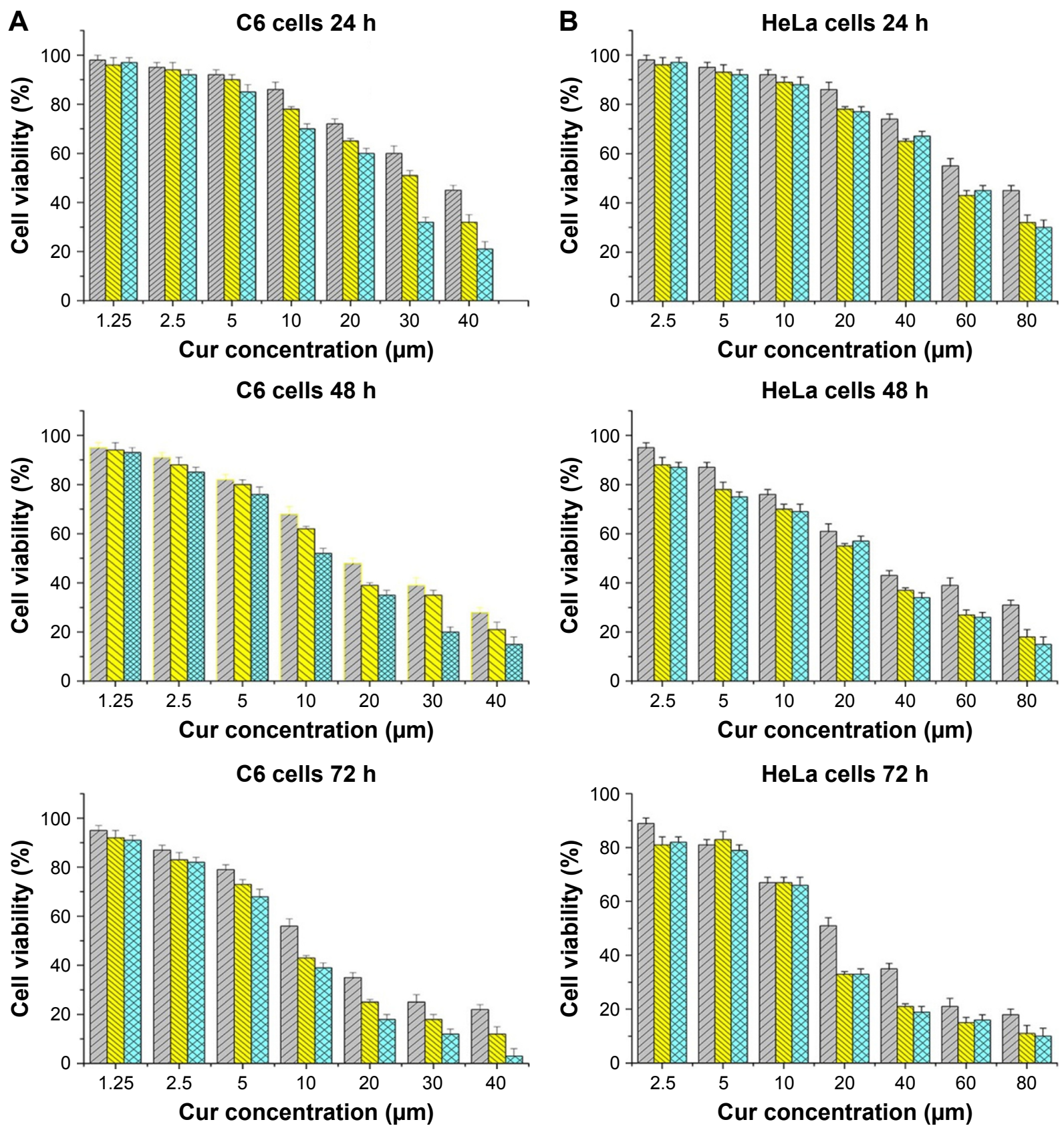

एय Free Cur $\square$ Cur-NP $ळ$ cHP/Cur-NP

Figure 5 Cytotoxicity of curcumin and its NPs on C6 cells (A) and HeLa cells (B).

Notes: The cells were incubated with free curcumin, Cur-NPs, or cHP/Cur-NP for 24,48 , or $72 \mathrm{~h}$ at $37^{\circ} \mathrm{C}$ before the MTT assay.

Abbreviations: cHP, cyclic hexapeptide, c(RGDf(N-me)VK)-C; cHP/Cur-NP, cHP-modified curcumin nanoparticles; Cur, curcumin; Cur-NP, curcumin nanoparticles; MTT, 3-(4,5-dimethylthiazol-2-Yl)-2,5-diphenyltetrazolium bromide; NPs, nanoparticles.

viabilities for treatment with free curcumin, Cur-NPs, and cHP/Cur-NPs were $86.2 \%, 78.6 \%$, and $77.1 \%$, respectively. Curcumin NPs had a higher cytotoxicity than free curcumin, but the cell viability was similar between Cur-NPs and cHP/ Cur-NPs. In addition, extended incubation times increased the cytotoxicity of equal curcumin concentrations. In these experiments, curcumin showed a lower cytotoxicity in C6 and HeLa cells than the corresponding NPs due to the improved biocompatibility and affinity to cells of the PEG-PLGA incorporated in the NPs. ${ }^{24}$

The cHP/Cur-NPs were more lethal to $\mathrm{C} 6$ cells than Cur-NPs in the low integrin-expressing HeLa cells. In HeLa cells, no significant difference was observed in the cytotoxicity between Cur-NPs and cHP/Cur-NPs in most cases, possibly because the RGD sequence peptides can bind to integrin- $\alpha_{v} \beta_{3}$ in C6 cells but not in HeLa cells, ${ }^{25,26}$ and the 
retention time and cellular uptake efficiency of the NPs can be greatly improved by receptor-mediated endocytosis of the existing targeted ligands. ${ }^{27}$ The experimental cytotoxicity data indicated that the effect of Cur-NPs coupled with cyclic hexapeptide on cells was concentration and time dependent. After a 24-h incubation with $10 \mu \mathrm{M}$ cHP/Cur-NPs, 70\% of $\mathrm{C} 6$ cells were alive; therefore, the cells were incubated with curcumin for less time in subsequent in vitro cellular targeting evaluations.

\section{In vitro cellular targeting of NPs in C6 cells}

To evaluate the ability of the cyclic hexapeptide-modified Cur-NPs to specifically recognize high integrin $\alpha_{v} \beta_{3}$ expressing cells, the cellular uptake efficiency of the Cur-NPs and cHP/Cur-NPs in C6 cells was determined by flow cytometry. The results are shown in Figure 6. In this experiment, curcumin was used as a fluorescent indicator for detecting the ratio of fluorescence in the cells.

For the cHP/Cur-NP and Cur-NP groups $(n=3)$, the average cellular uptake efficiency of Cur-NPs was dependent on incubation time. At a concentration of $10 \mu \mathrm{M}$, the cellular uptake efficiency of the cHP/Cur-NP group reached $38.3 \%$ after $30 \mathrm{~min}$ of treatment. In addition, the average cellular uptake efficiency of Cur-NPs was $19.4 \%$ at $30 \mathrm{~min}$, which was significantly decreased compared with that of the cHP/ Cur-NP group $(P<0.01)$. With increasing incubation time, the cellular uptake efficiency of the two groups increased correspondingly. For $90 \mathrm{~min}$ of culture time, the uptake

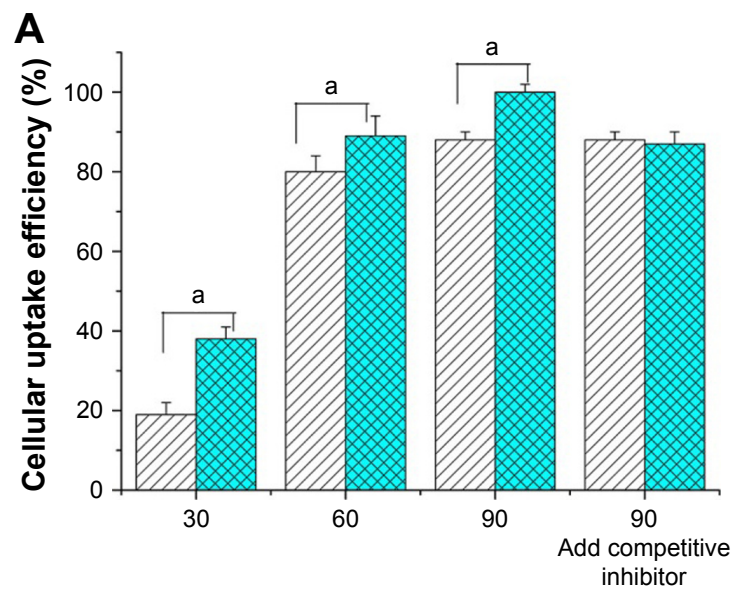

Treatment time (min) efficiency of the cHP/Cur-NP group reached 99.5\%. At all treatment times, the cHP/Cur-NP group had a better cell uptake efficiency than the Cur-NP group $(P<0.01)$. After pre-incubation for $1 \mathrm{~h}$ with a competitive integrin $\alpha_{\mathrm{v}} \beta_{3}$ inhibitor, the cell uptake efficiencies of the cHP/Cur-NP and Cur-NP groups were $87.6 \%$ and $88.3 \%$, respectively, at 90 min of incubation, and no significant difference was observed between these two groups. These data presented that the different cell uptake efficiencies for cells treated with the cHP/Cur-NPs and Cur-NPs were related to the affinity of cyclic hexapeptide with the integrin on the surface of C6 cells. When the integrin was conjugated with free cyclic hexapeptide, the Cur-NPs modified by cyclic hexapeptide could not specifically recognize C6 cells. Therefore, the cell uptake efficiency of the cHP/Cur-NPs was similar to the Cur-NP group.

To further investigate the cellular uptake efficiency of cHP/Cur-NPs, we studied the dose-dependent relationship of the NPs in C6 cells via flow cytometry. The uptake efficiency of Cur-NPs and cHP/Cur-NPs showed a positive dose-efficiency relationship (Figure 6, right). The cell uptake efficiency of curcumin NPs increased with increasing concentrations of curcumin, and significant differences between the cHP/Cur-NP and Cur-NP groups $(P<0.01)$ were observed at all concentrations.

The experimental results indicated that the cHP/Cur-NPs had a significant capacity to specifically recognize C6 cells because they had a better affinity for C6 cells $\left(\alpha_{\mathrm{v}} \beta_{3}{ }^{+}\right)$than the Cur-NPs for promoting the cellular uptake of the NPs.

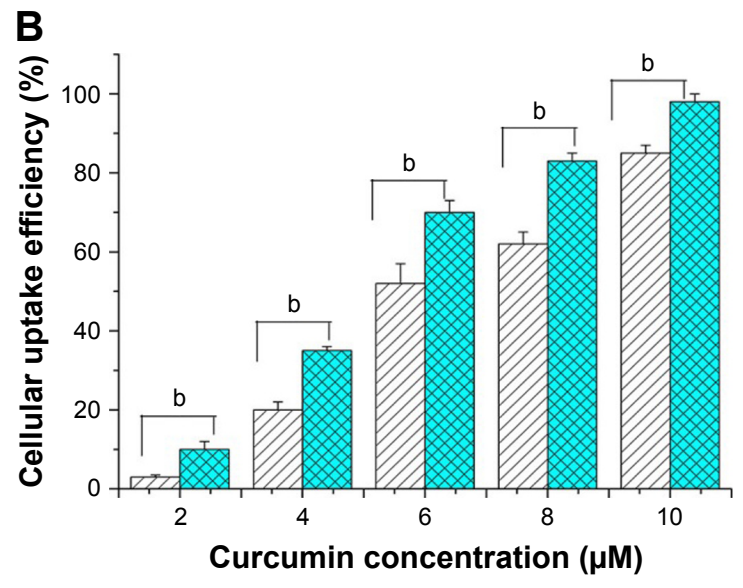

$$
\text { EIJ Cur-NP } \times \text { cHP/Cur-NP }
$$

Figure 6 (A) Cellular uptake efficiency of C6 cells incubated with $10 \mu \mathrm{M}$ Cur-NPs or cHP/Cur-NPs for different treatment times as tested by flow cytometry. (B) Cellular uptake efficiency of $\mathrm{C} 6$ cells incubated with different concentrations of Cur-NPs and cHP/Cur-NPs for 90 min.

Notes: The letters "a" and "b" indicate significant differences between the two groups; $P<0.0$.

Abbreviations: cHP, cyclic hexapeptide, c(RGDf(N-me)VK)-C; cHP/Cur-NPs, cHP-modified curcumin nanoparticles; Cur-NPs, curcumin nanoparticles. 


\section{In vitro cellular penetration of NPs to $\mathrm{C} 6$ spheroids}

In the above experiments, compared to Cur-NPs, the cHP/ Cur-NPs showed better targeting ability for monolayer cancer cells that highly express integrin $\alpha_{\mathrm{v}} \beta_{3}$. However, this benefit might not be a key to cancer treatment because of tumor drug resistance mechanisms. ${ }^{28}$ Cancer cell spheroids represent a better model of drug resistance than monolayer cells. Therefore, we established a tumor cell spheroid model for evaluating the penetration of Cur-NPs into tumor tissue in vitro. ${ }^{29}$ In this experiment, curcumin is not suitable for observing drug penetration into compact cell spherical entities because of its weak fluorescence. Therefore, coumarin was used as an indicator instead of curcumin in these experiments.

Agarose was added to 96-well plates, and C6 cells were then cultured in the wells. The cell aggregates grew and gradually formed tight tumor spheres. The growth states of the cells at 1,2, and $5 \mathrm{~d}$ are shown in Figure 7A. The tight spheroids were used for the experiment.

Penetration of the cHP/Cou-NPs into the C6 spheroids was observed via confocal microscopy, and the results are presented in Figure 7B and C. The image shows that fluorescence was observed on the periphery of the cell spheroids after a short time of incubation with $\mathrm{cHP} / \mathrm{Cou}-$ NPs that were modified by the cyclic hexapeptide. This result indicated that the $\mathrm{cHP} / \mathrm{Cou}-\mathrm{NPs}$ had gathered at the surface of the tumor spheroids. With increased incubation time, the fluorescence became uniformly distributed in the spheroids, and the intensity gradually increased. The CouNPs, which were not modified with cyclic hexapeptide, exhibited difficulty in penetrating the C6 tumor spheroids, and weak fluorescence was observed in each spheroid at various time points. These results indicated that the cHP/ Cou-NPs had a stronger ability to penetrate the tight tumor tissue due to the presence of cyclic hexapeptide. The addition of the cyclic hexapeptide improved the cell specificity recognition and nanoparticle uptake, and these NPs showed similar results with the in vitro cellular targeting of NPs in C6 monolayer cells.

\section{In vivo targeting of NPs in a rat glioma model}

The infiltrative nature of glia and the existence of the BBB are responsible for the failure of surgery and chemotherapy to completely remove gliomas..$^{30}$ Modeling this process in vivo will lead to a better simulation of the pathophysiology of gliomas and improved evaluations of the targeting ability of NPs to gliomas.

On the basis of our results, cyclic hexapeptide can allow NPs to target C6 cells overexpressing integrins. However, for gliomas, which grow at specific sites and are protected by

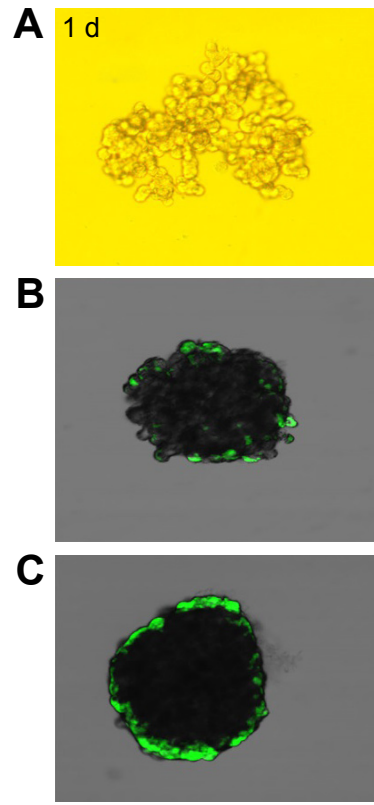

$1 \mathrm{~h}$
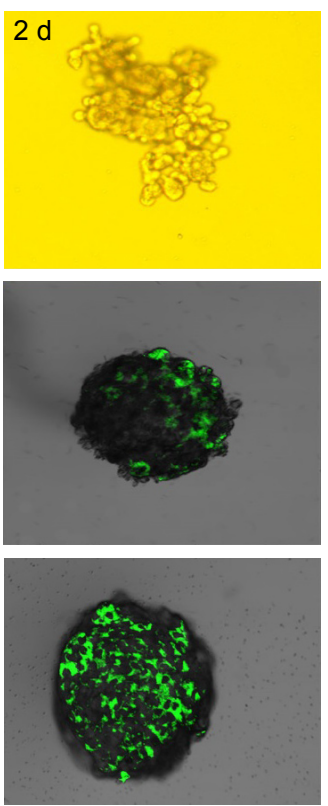

$2 \mathrm{~h}$
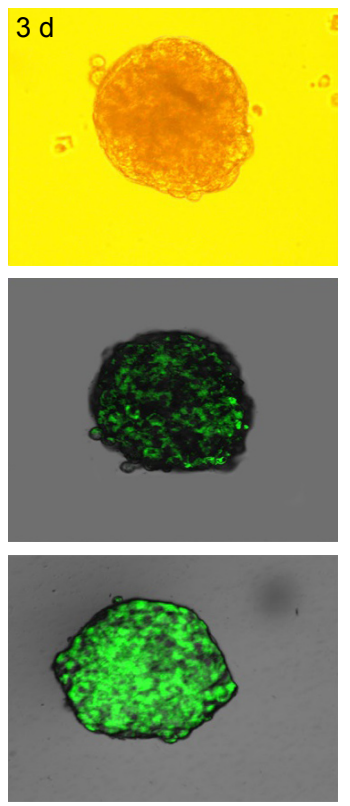

$4 \mathrm{~h}$

Figure 7 Growth state of tumor spheres as observed under an optical microscope at different culture times (A). Confocal fluorescence microscopy images of Cou-NPs (B) and cHP/Cou-NPs (C) throughout $\mathrm{C} 6$ spheroids at different treatment times.

Abbreviations: cHP, cyclic hexapeptide, c(RGDf(N-me)VK)-C; cHP/Cou-NPs, cHP-modified coumarin nanoparticles; Cou-NPs, coumarin nanoparticles. 


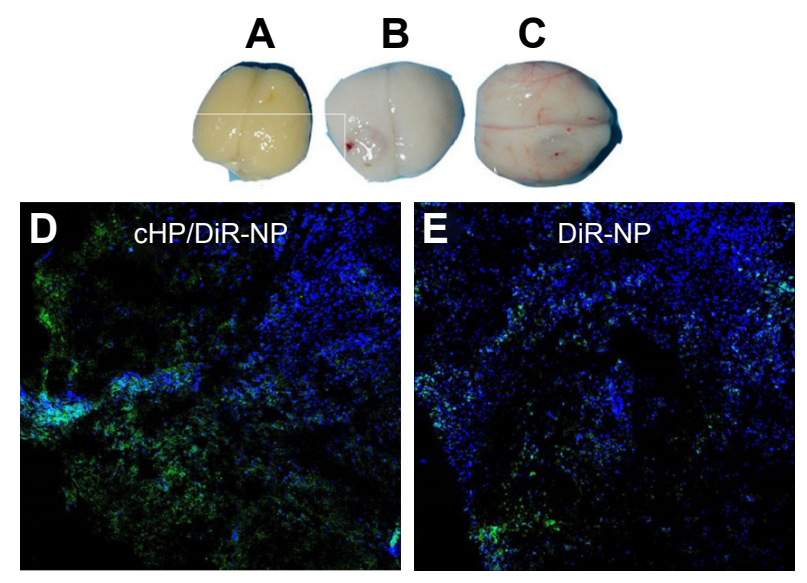

Figure 8 Ex vivo imaging of brains excised from SD rats of the sham surgery group I d after PBS injection (A) and from the surgery group at I4 d (B) and 2 I d (C) after C6 cell injection. Confocal fluorescence microscopy images of cHP/DiR-NPs (D) and DiR-NPs (E) in tumor tissue $8 \mathrm{~h}$ after NP injection.

Abbreviations: cHP, cyclic hexapeptide, c(RGDf(N-me)VK)-C; cHP/DiR-NPs, cHP-modified DiR nanoparticles; DiR, I, I'-Dioctadecyl-3,3,3',3'-tetramethylindotricarbocyanine; DiR-NPs, DiR nanoparticles; SD, Sprague-Dawley.

the BBB, the targeting of the drug delivery system requires further studies for validation in in vivo gliomas. To investigate the targeting of NPs modified with a cyclic hexapeptide in a pathological condition, a glioma model was developed using C6 cells in rats. DiR was used as a tracing agent for in vivo imaging instead of curcumin and was encapsulated into NPs and NPs modified with cyclic hexapeptide to monitor their distributions in tumor-bearing rats.

We established a C6 glioma model in SD rats using a stereotaxic apparatus, and images of the brains and tumors for each group are presented in Figure 8A-C. Twenty-one days after the injection of PBS, the brains of rats in the sham surgery group exhibited no significant changes in appearance. In the surgery group, $\mathrm{C} 6$ cells were injected into the brains of test rats, and the brains gradually changed in appearance as time progressed. At 14 and $21 \mathrm{~d}$ after the injection of tumor cells, gliomas formed gradually, and significant midline shifts occurred due to tumor extrusion. Therefore, in subsequent experiments, rats were used at $21 \mathrm{~d}$ after injection of $\mathrm{C} 6$ cells.

Confocal fluorescence images of cHP/DiR-NPs and DiR-NPs in tumor tissue after NP injection for $8 \mathrm{~h}$ in $\mathrm{C} 6$ glioma rats are shown in Figure 8D and E. The blue regions in the image are nuclei stained with Hochest33342, and the green fluorescence indicates DiR encapsulated in the NPs. The green fluorescence signal in the cHP/DiR-NP group was stronger than that in the DiR-NP group.

Figure 9 shows in vivo fluorescence images of $\mathrm{C} 6$ gliomas of SD rats at 1, 4, 8, 12, and $24 \mathrm{~h}$ after the tail vein injection of free DiR-NPs or cHP/DiR-NPs. For the cHP/DiR-NP group, a weak fluorescence signal was observed in the brain

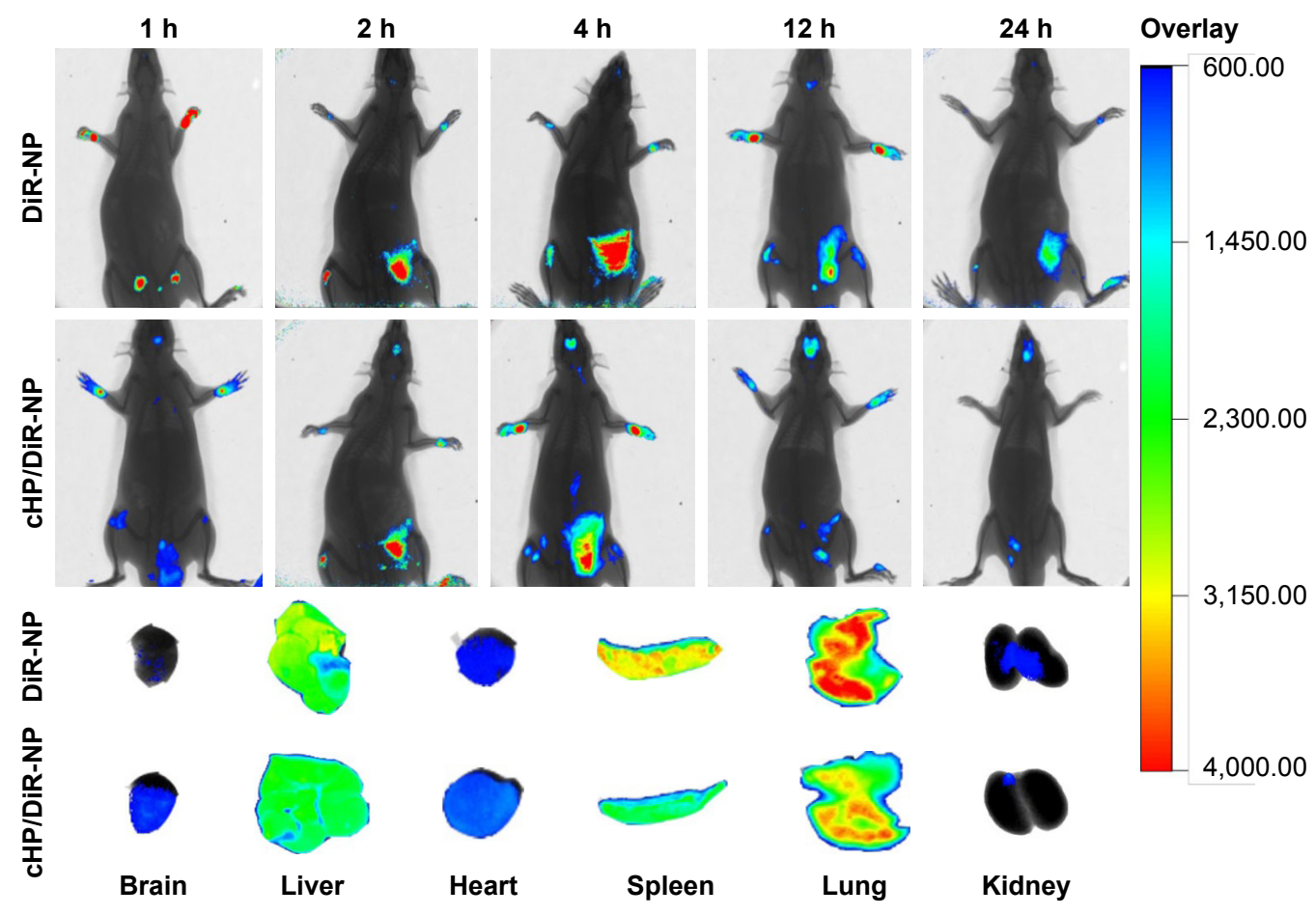

Figure 9 In vivo imaging of C6 gliomas in SD rats at I, 4, 8, I2, and $24 \mathrm{~h}$ after intravenous injection of DiR-NPs or cHP/DiR-NPs (300 $\mu$ g/kg). Note: Ex vivo imaging of organs excised from SD rats with $\mathrm{C} 6$ gliomas $24 \mathrm{~h}$ after injection.

Abbreviations: cHP/DiR-NPs, cHP-modified DiR nanoparticles; DiR, I,I'-Dioctadecyl-3,3,3',3'-tetramethylindotricarbocyanine; DiR-NPs, DiR nanoparticles; SD, SpragueDawley. 
$1 \mathrm{~h}$ after injection, and the signal increased gradually as time progressed. At $12 \mathrm{~h}$ after injection, the signal reached a maximum and was still observed in the brain at $24 \mathrm{~h}$. For the DiR-NP group, a fluorescent signal in the tumor appeared at $4 \mathrm{~h}$ post-injection and reached a maximum at $12 \mathrm{~h}$. The rats in the cHP/DiR-NP group exhibited a stronger signal in the tumor compared with the rats in the DiR-NP group at all points. Due to the thickness of the rat's body, it is difficult to observe the fluorescent signal distribution of NPs in the other organs within the animal. Fluorescence signals were observed only in the superficial brain and abdomen. Therefore, the fluorescence images of the excised tissues obtained after $24 \mathrm{~h}$ are shown in Figure 9 to further confirm the DiR-NP distribution. The image shows that the fluorescent signal of the brain in the cHP/DiR-NP group was significantly stronger than that in the DiR-NP group. The fluorescent cHP/DiRNPs of the excised tissues were successively distributed in the lungs, spleen, liver, brain, heart, and kidneys. The signals in the brain of the cHP/DiR-NP group were stronger than that of the DiR-NP group. Similar to our earlier results in the C6 ectopic tumors (presented in the Supplementary materials), fewer cHP/DiR-NPs were observed in the lungs, spleens, and kidneys of the glioma rats than DiR-NPs in the respective groups.

Although in vivo targeting of NPs in the rat glioma model is only a qualitative experiment, this result further highlights that NPs modified with a cyclic hexapeptide can pass through the BBB and accumulate in a targeted manner in glioma tumor tissues.

\section{Conclusion}

In this study, various cyclic hexapeptides were screened via computer simulation docking and in vitro cell evaluations. The cyclic hexapeptide of $\mathrm{c}(\mathrm{RGDf}(\mathrm{N}-\mathrm{me}) \mathrm{VK})-\mathrm{C}$, which exhibited strong affinity to integrin $\alpha_{v} \beta_{3}$-overexpressing cells, enhanced targeting specificity, as demonstrated through an in vitro cell evaluation. $c($ RGDf(N-me)VK)-C and PEG-PLGA conjugates were successfully synthesized. Cur-NPs modified with cyclic hexapeptides were prepared through the self-assembly method and they exhibited a spherical shape and a narrow size distribution. The NPs could specifically target monolayer cells and cell spheroids overexpressing integrin $\alpha_{\mathrm{v}} \beta_{3}$. The in vitro cytotoxicity of the cyclic hexapeptide-modified cHP/Cur-NPs was higher than that of free curcumin and Cur-NP because of their superior ability to target tumor neovascularization and tumor cells. Compared with NPs not modified with cyclic hexapeptides, the NPs modified with cyclic hexapeptides show better penetration and aggregation ability in the brain of glioma rats and less distribution in the lungs and spleens. These results demonstrated that $\mathrm{c}(\mathrm{RGDf}(\mathrm{N}-\mathrm{me}) \mathrm{VK})-\mathrm{C}$ can serve as an effective targeting ligand, and the Cur-NPs modified with the cyclic hexapeptides can be exploited as a potential drug delivery system for targeting gliomas. In future studies, we will continue to evaluate their therapeutic efficacy in animal glioma models.

\section{Acknowledgments}

This work was supported by the Natural Science Foundation of Shandong (grant number ZR2014HM062) and the National Science and Technology Major Project (grant number 2013ZX09402201).

\section{Disclosure}

The authors report no conflicts of interest in this work.

\section{References}

1. Price RL, Chiocca EA. Evolution of malignant glioma treatment: from chemotherapy to vaccines to viruses. Neurosurgery. 2014;61(Suppl 1): 74-83.

2. Qin L, Wang CZ, Fan HJ, et al. A dual-targeting liposome conjugated with transferrin and arginine-glycine-aspartic acid peptide for gliomatargeting therapy. Oncol Lett. 2014;8(5):2000-2006.

3. Pardridge WM. Brain drug development and brain drug targeting. Pharm Res. 2007;24(9):1729-1732.

4. Alnaami IM, Al-Nuaimi SK, Senthilselvan A, et al. Effectiveness of adjuvant temozolomide treatment in patients with glioblastoma. Neurosciences (Riyadh). 2013;18(4):349-355.

5. Oberoi RK, Parrish KE, Sio TT, Mittapalli RK, Elmquist WF, Sarkaria JN. Strategies to improve delivery of anticancer drugs across the blood-brain barrier to treat glioblastoma. Neuro Oncol. 2016;18(1): 27-36.

6. Vartanian A, Singh SK, Agnihotri S, et al. GBM's multifaceted landscape: highlighting regional and microenvironmental heterogeneity. Neuro Oncol. 2014;16(9):1167-1175.

7. Kurozumi K, Ichikawa T, Onishi M, Fujii K, Date I. Cilengitide treatment for malignant glioma: current status and future direction. Neurol Med Chir (Tokyo). 2012;52(8):539-547.

8. Mas-Moruno C, Rechenmacher F, Kessler H. Cilengitide: the first antiangiogenic small molecule drug candidate design, synthesis and clinical evaluation. Anticancer Agents Med Chem. 2010;10(10):753-768.

9. Vick NA, Khandekar JD, Bigner DD. Chemotherapy of brain tumors. Arch Neurol. 1977;34(9):523-526.

10. Herve F, Ghinea N, Scherrmann JM. CNS delivery via adsorptive transcytosis. AAPS J. 2008;10(3):455-472.

11. Sugahara KN, Teesalu T, Karmali PP, et al. Tissue-penetrating delivery of compounds and nanoparticles into tumors. Cancer Cell. 2009; 16(6):510-520.

12. Senft C, Polacin M, Priester M, Seifert V, Kogel D, Weissenberger J. The nontoxic natural compound curcumin exerts anti-proliferative, anti-migratory, and anti-invasive properties against malignant gliomas. BMC Cancer. 2010;10:491.

13. Yallapu MM, Jaggi M, Chauhan SC. Curcumin nanoformulations: a future nanomedicine for cancer. Drug Discov Today. 2012;17(1-2): 71-80.

14. Wadhwa J, Asthana A, Gupta S, Shilkari Asthana G, Singh R. Development and optimization of polymeric self-emulsifying nanocapsules for localized drug delivery: design of experiment approach. Scientific World Journal. 2014;2014:516069. 
15. Xiong JP, Stehle T, Diefenbach B, et al. Crystal structure of the extracellular segment of integrin $\alpha v \beta 3$. Science. 2001;294(5541):339-345.

16. Chen $\mathrm{H}, \mathrm{Niu} \mathrm{G}, \mathrm{Wu} \mathrm{H}, \mathrm{Chen} \mathrm{X}$. Clinical application of radiolabeled RGD peptides for PET imaging of integrin $\alpha v \beta 3$. Theranostics. 2016; 6(1):78-92.

17. Liu S. Radiolabeled cyclic RGD peptides as integrin $\alpha v \beta 3$-targeted radiotracers: maximizing binding affinity via bivalency. Bioconjugate Chem. 2009;20(12):2199-2213.

18. Liu X, Wang W, Samarsky D, et al. Tumor-targeted in vivo gene silencing via systemic delivery of cRGD-conjugated siRNA. Nucleic Acids Res. 2014;42(18):11805-11817.

19. Yu KF, Zhang WQ, Luo LM, et al. The antitumor activity of a doxorubicin loaded, iRGD-modified sterically-stabilized liposome on B16-F10 melanoma cells: in vitro and in vivo evaluation. Int $J$ Nanomedicine. 2013;8:2473-2485.

20. Perche F, Torchilin VP. Cancer cell spheroids as a model to evaluate chemotherapy protocols. Cancer Biol Ther. 2012;13(12):1205-1213.

21. Gao H, Hu Y, Xiong Y, et al. Glioma targeting and anti-glioma effect of interleukin 13 peptide and RGD peptide dual functionalized nanoparticles. Curr Pharm Biotechnol. 2014;14(13):1118-1126.

22. Sawant RR, Torchilin VP. Challenges in development of targeted liposomal therapeutics. AAPS J. 2012;14(2):303-315.

23. Borgne-Sanchez A, Dupont S, Langonne A, et al. Targeted Vpr-derived peptides reach mitochondria to induce apoptosis of $\alpha \mathrm{v} \beta 3$-expressing endothelial cells. Cell Death Differ. 2007;14(3):422-435.
24. Fu YC, Fu TF, Wang HJ, et al. Aspartic acid-based modified PLGAPEG nanoparticles for bone targeting: in vitro and in vivo evaluation. Acta Biomater. 2014;10(11):4583-4596.

25. Trusolino L, Serini G, Cecchini G, et al. Growth factor-dependent activation of $\alpha \mathrm{V} \beta 3$ integrin in normal epithelial cells: implications for tumor invasion. $J$ Cell Biol. 1998;142(4):1145-1156.

26. Liu Z, Liu S, Wang F, Liu S, Chen X. Noninvasive imaging of tumor integrin expression using 18F-labeled RGD dimer peptide with PEG4 linkers. Eur J Nucl Med Mol Imaging. 2009;36(8):1296-1307.

27. Shi J, Votruba AR, Farokhzad OC, Langer R. Nanotechnology in drug delivery and tissue engineering: from discovery to applications. Nano Lett. 2010;10(9):3223-3230.

28. Tannock IF, Lee CM, Tunggal JK, Cowan DS, Egorin MJ. Limited penetration of anticancer drugs through tumor tissue: a potential cause of resistance of solid tumors to chemotherapy. Clin Cancer Res. 2002;8(3): 878-884.

29. Sethi P, Jyoti A, Swindell EP, et al. 3D tumor tissue analogs and their orthotopic implants for understanding tumor-targeting of microenvironment-responsive nanosized chemotherapy and radiation. Nanomedicine. 2015;11(8):2013-2023.

30. DeArmond SJ, Stowring L, Amar A, et al. Development of a nonselecting, non-perturbing method to study human brain tumor cell invasion in murine brain. J Neurooncol. 1994;20(1):27-34. 


\section{Supplementary materials}

In vivo targeting evaluation in ectopic

tumors of nude mice

\section{Methods}

C6 cells $\left(5 \times 10^{6}\right.$ per mice) were transplanted into the right forelimbs of nude mice (weighing 16-22 g), and the mice were used in subsequent experiments $\sim 1$ month later, when the tumors had grown to $\sim 800 \mathrm{~mm}^{3}$.

Six tumor-bearing nude mice were randomly divided into three groups, and $0.2 \mathrm{~mL}$ of 1,1'-Dioctadecyl-3,3,3',3'tetramethylindotricarbocyanine (DiR) nanoparticles (DiR-NPs), cyclic hexapeptide, c(RGDf(N-me)VK)-C (cHP)-modified DiR nanoparticles (cHP/DiR-NPs), or DiR solution was injected ( $300 \mu \mathrm{g} / \mathrm{kg}$ i.v.) into the mice. At 1, 4, $6,8,10,12$, and $24 \mathrm{~h}$ after injection, the mice were anesthetized with 5\% chloral hydrate. In vivo imaging (Care stream In Vivo FX, Bruker, Madison, WI, USA) was performed to screen the fluorescence distribution and assess the in vivo targeting ability of the NPs. At $8 \mathrm{~h}$ post-injection, the mice were euthanized, and the tumor and certain organs were harvested. The fluorescent images of the tumors and organs were recorded and analyzed using Kodak MI In Vivo Fx Pro software (Kodak, Rochester, NY, USA).

\section{Results}

To investigate the targeting of NPs modified with a cyclic hexapeptide in a pathological condition, an ectopic tumor model was developed using $\mathrm{C} 6$ cells in the forelimbs of nude mice. Instead of curcumin, DiR was used as a tracing agent for in vivo imaging and was encapsulated into NPs and NPs modified with a cyclic hexapeptide to monitor their distributions in tumor-bearing nude mice. Figure S1A shows in vivo fluorescence images of $\mathrm{C} 6$ tumor-bearing nude mice at $1,4,6,8,10,12$, and $24 \mathrm{~h}$ after tail vein injection of free DiR, DiR-NPs, or cHP/DiR-NPs. For the cHP/DiR-NP group, weak fluorescence was observed in the tumor $4 \mathrm{~h}$ after injection, and the signal gradually increased thereafter. At $8 \mathrm{~h}$ after injection, the signal reached a maximum value and was still detectable in the tumors at $24 \mathrm{~h}$. For the DiR-NP group, a fluorescent signal appeared in the tumor at $6 \mathrm{~h}$ postinjection and reached a maximum at $8 \mathrm{~h}$. However, the signal rapidly weakened thereafter, and very weak fluorescence was observed at the last time point. Free DiR can easily enter all tissues and tumors, but the distribution of free DiR in the tumors was low due to its broad tissue distribution. Therefore, the fluorescence signal in the free DiR group appeared earlier than in the other two groups, but its signal strength was weak at all time points. For the two NP groups, the mice in the cHP/DiR-NP group presented a stronger signal in the tumor tissue than the mice in the DiR-NP group at most time points. This result indicates that DiR-NPs modified with a cyclic hexapeptide have a better targeting effect than DiRNPs that are not modified with a cyclic hexapeptide.

Figure S1B shows fluorescence images of the excised tissues acquired $8 \mathrm{~h}$ after treatment initiation, which further confirmed the distribution of free DiR and its NPs. As shown in the image, the fluorescent signal of the tumor in the cHP/ DiR-NP group was stronger than that in the other groups. This finding further emphasized that cyclic hexapeptide-modified NPs aggregate better in tumors than NPs not modified with cyclic hexapeptide. In the free DiR group, the signal observed in the liver tissue was the strongest, followed by signals in the

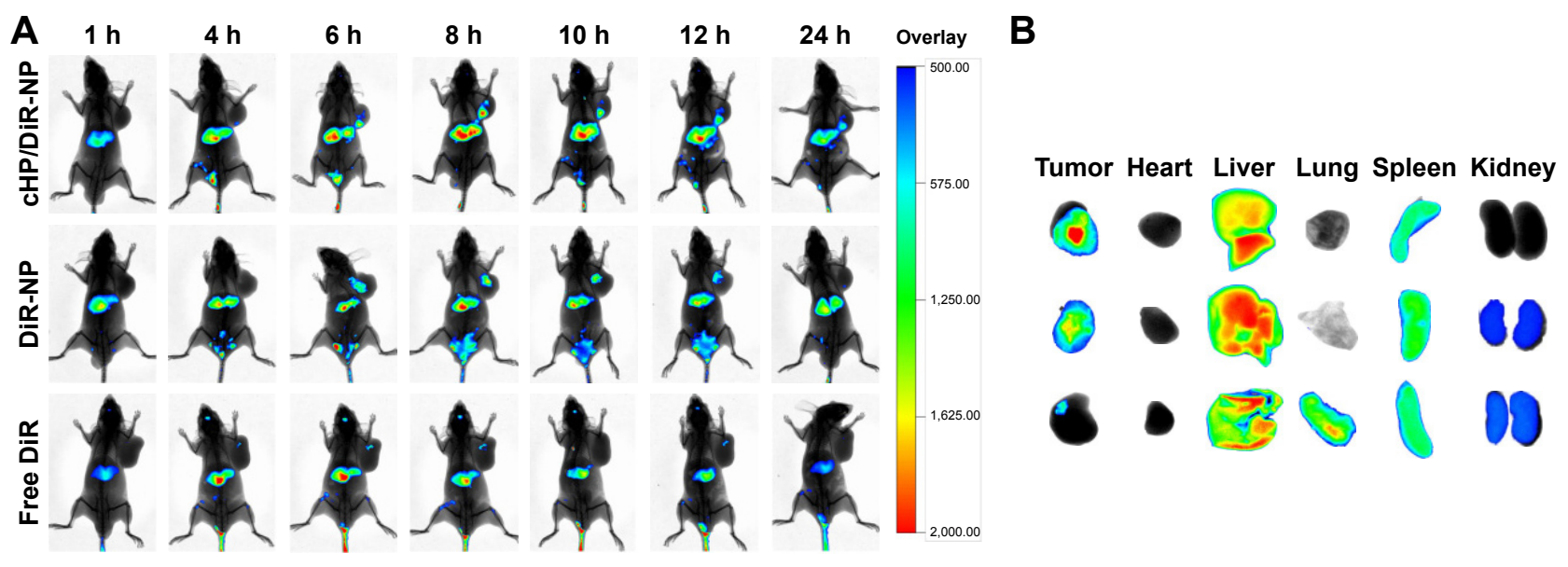

Figure SI (A) In vivo imaging of C6 ectopic tumors of nude mice at I, 4, 6, 8, I2, and 24 h after i.v. injection of DiR-Np, cHP/DiR-Np, or DiR solution (300 $\mu$ g/kg i.v.). (B) Ex vivo imaging of tumors and organs that were excised from $\mathrm{C} 6$ ectopic tumors of nude mice at $8 \mathrm{~h}$.

Abbreviations: cHP, cyclic hexapeptide, c(RGDf(N-me)VK)-C; cHP/DiR-Np, cHP-modified DiR nanoparticles; DiR, I, I'-Dioctadecyl-3,3,3',3'-tetramethylindotricarbocyanine; DiR-Np, DiR nanoparticles; i.v., intravenous. 
lungs, spleen, and tumor. The signal strength in tumor of the free DiR group was significantly weaker than the signals in the two NP groups. The NPs of the two NP groups were also primarily distributed in the liver for phagocytosis and ingestion by macrophages, ${ }^{1}$ followed by distribution in the tumor, spleen, and kidneys. As expected, the signal in the tumor tissue of the cHP/DiR-NP group was significantly stronger than that of the DiR-NP group because the enhanced permeability and retention effect at the tumor site increases NP accumulation. In addition, $\alpha_{\mathrm{v}} \beta_{3}$ integrin-overexpressing $\mathrm{C} 6$ cells can also increase the specific binding to cyclic hexapeptide in the cHP/DiR-NP group. The aggregate fluorescence in the lungs and kidneys of the tumor-bearing nude mice was lower in the cHP/DiR-NP group than in the other two groups. This finding demonstrated that the cyclic hexapeptide could target integrin-overexpressing tumors.

\section{Reference}

1. Davis ME, Chen ZG, Shin DM. Nanoparticle therapeutics: an emerging treatment modality for cancer. Nat Rev Drug Discov. 2008;7(9): $771-782$.

\section{Publish your work in this journal}

The International Journal of Nanomedicine is an international, peerreviewed journal focusing on the application of nanotechnology in diagnostics, therapeutics, and drug delivery systems throughout the biomedical field. This journal is indexed on PubMed Central, MedLine, CAS, SciSearch $®$, Current Contents ${ }^{\circledR} /$ Clinical Medicine,
Journal Citation Reports/Science Edition, EMBase, Scopus and the Elsevier Bibliographic databases. The manuscript management system is completely online and includes a very quick and fair peer-review system, which is all easy to use. Visit http://www.dovepress.com/ testimonials.php to read real quotes from published authors. 